\title{
LA IDEA DE DIOS COMO MISTERIO EN EL GÉNESIS DEL MÉTODO CIENTÍFICO DE GALILEO GALILEI
}

\author{
Janina Navarro Linares \\ Universidad Católica Sedes Sapientiae \\ jnavarro@ucss.edu.pe
}

Cuando contemplo tu cielo, obra de tus dedos, la luna y las estrellas que has dispuesto, ¿qué es el hombre para que te acuerdes de él, el hijo de Adán para que te ocupes de él?

(Salmo 8)

Fecha de recepción: agosto de 2014 Fecha de aceptación: octubre de 2014

Resumen: Los estudios históricos y filosóficos han evidenciado el origen de la ciencia moderna a partir de las nuevas concepciones del mundo físico de Galileo Galilei que resultaron ser contrarias a la física aristotélica. El objetivo del presente trabajo es identificar cómo la idea de Dios como Misterio y la concepción cristiana del mundo, del cual deriva a partir de lo primero, han aportado de modo relevante en la nueva concepción de la ciencia física para Galileo y le ha facilitado establecer de manera definitiva el método de la ciencia natural. Para realizar este recorrido, nos apoyaremos con los textos de Stillman Drake (Galileo) y Eugenio Garín (Ciencia y vida civil en el renacimiento italiano) comparándolos con los textos de Paolo Musso (La scienza e l'idea di ragione) y Luigi Giussani (La conciencia 
religiosa en el hombre moderno) para explicar el contexto cultural de Galileo y el surgimiento de la ciencia moderna.

Palabras clave: Misterio, creación, ciencia moderna, Galileo Galilei, opción, método científico.

\section{THE IDEA OF GOD AS A MYSTERY IN THE GENESIS OF GALILEO GALILEI'S SCIENTIFIC METHOD}

Abstract: The historical and philosophical studies have evidenced the origin of modern science from the new conceptions of the physical world of Galileo Galilei found to be contrary to Aristotelian physics. The objective of this work is to identify how the idea of God as Mystery and Christian worldview, from which derives from the first, have contributed so relevant in the new conception of physical science to Galileo and facilitated it to establish definitively the method of natural science. To make this route, will support the texts of Stillman Drake (Galileo) and Eugenio Garin (Science and civic life in the Italian Renaissance), which will be compared with texts by Paolo Musso (La Scienza e l'notion di ragione) and Luigi Giussani (The religious consciousness in modern man) to explain the cultural context of Galileo and the rise of modern science.

KeYwords: Mystery, creation, modern science, Galileo Galilei, choice, scientific method. 


\section{LA LEYENDA DE LA ETERNA LUCHA ENTRE CIENCIA Y FE RELIGIOSA}

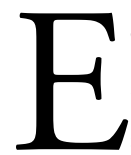

$s$ muy común escuchar en la actualidad que la ciencia y la fe religiosa no se pueden complementar dentro del trabajo científico debido a que la fe entorpece y dificulta la investigación científica. Es un concepto muy generalizado y muchas veces casi asumido dogmáticamente, sobre todo, en estos últimos siglos. ${ }^{1}$ Empero, en este trabajo se cuestionará si esto se cumple o no en la experiencia de la investigación científica; en especial, desde el actuar del científico. Se pondrá como referencia el caso de Galileo Galilei, porque se le reconoce como el padre de la ciencia moderna; esto quiere decir que logró establecer el método apropiado para la ciencia experimental, indicando la importancia del estudio de las propiedades de la materia.

La pregunta natural surge inmediatamente: ¡cómo Galileo pudo darse cuenta de algo que los demás filósofos naturales no tomaban en consideración de forma consciente? Galileo, claro, tenía su genialidad personal, pero hubo también muchos otros que no eran menos inteligentes que él. Por tanto, esto ciertamente tiene su importancia, pero no puede ser

1 Una muestra de ello se puede encontrar en una carta de Pierre Duhem (físico francés del fin del siglo XIX y principios del siglo xx) dirigida al Padre Bulliot, donde le explica el recorrido de esta confrontación entre ciencia y religión: «Se nos pinta con espanto aquella noche de la Edad Media durante la cual las escuelas, sometidas a las artimañas del cristianismo, únicamente preocupadas por las discusiones teológicas, no supieron recoger ni la menor parcela de la herencia científica de los griegos. Se hacen resplandecer ante nuestros ojos los descubrimientos del Renacimiento, en el cual las mentes, liberadas por fin del yugo de la Iglesia, volvieron a encontrar el hilo de la tradición científica, al mismo tiempo que el secreto de la belleza artística y literaria. A partir del siglo XVI suele oponerse, con complacencia, la marcha siempre ascendente de la ciencia a la decadencia, cada vez más profunda, de la religión [...] Esto es lo que se enseña en innumerables cátedras, lo que se escribe en multitud de libros» (Jaki 1996: 218-219). 
el factor determinante; ni puede serlo únicamente la coyuntura de cambios y concepciones nuevas sobre el mecanicismo (Cf. Duhem 1996), sino que, en el fondo, la contribución de Galileo ha sido por dos factores: (a) establecer de manera definitiva el método natural a partir de la fe cristiana en la creación y (b) una disposición de humildad frente a la realidad, a partir del concepción cristiana de Dios como Misterio. Este último punto, sobre todo, es el tema de investigación de este trabajo, ya que se postulará que fue esto lo que movió y forjó el carácter científico de Galileo y nueva ciencia moderna.

Por otro lado, este trabajo será de naturaleza teórica-reflexiva trabajada principalmente a partir de documentaciones galileanas, textos de tres autores especialistas en Galileo y un autor contemporáneo que abarca la dimensión filosófica-religiosa del pensamiento moderno. El primer bloque teórico corresponde al análisis y confrontación entre dos tendencias filosóficas: la primera, conformada por los libros biográficos e históricos de Stillman Drake (Galileo) y Eugenio Garín (Ciencia y vida civil en el renacimiento italiano), donde se sintetizará el recorrido histórico y el origen del cambio de mentalidad galileana propuesto por ellos; la segunda, conformada por los libros de Paolo Musso (La scienza e l'idea di ragione) y Luigi Giussani (La conciencia religiosa en el hombre moderno), en donde se evidencia que el clima cultural italiano, de donde surge la ciencia moderna, deriva de la tradición cristiana del mundo y que el modo de afrontar los grandes cambios modernos implica una opción hacia un reconocimiento del Misterio que permite esa facilidad de apertura hacia la novedad de la realidad. Se complementará con los aportes de la famosa carta a la archiduquesa de Toscana, la Serenísima Cristina de Lorena, que también nos es muy relevante porque se evidencia que no existe una confrontación 
entre los nuevos descubrimientos científicos — que luego conllevarán su defensa del heliocentrismo»- con las verdades reveladas en las Sagradas Escrituras; vale decir, no hay confrontación entre ciencia y religión cristiana.

Otros materiales complementarios recurrentes han sido los libros de William Shea y Mariano Artigas (Galileo en Roma. Crónica de 500 días) cuyas investigaciones sobre la figura galileana han sido de mucha ayuda y la de Stanley Jaki (La ciencia y la fe: Pierre Duhem donde relata, desde la visión de un científico contemporáneo (Pierre Duhem), lo que considera crucial para la realización teórica y originaria de la práctica científica.

\section{PUNTO DE PARTIDA: EL CONTEXTO HISTÓRICO DE GALILEO}

La vida en el siglo XV es muy competitiva para aquel que desea vivir de las ciencias o el arte. La fama y la pertenencia social eran invaluables. Desde este aspecto, Galileo se sentía muy orgulloso de pertenecer a una genealogía de gran reputación. Con respecto a su familia, gran parte de su formación y actitud se las debía a su padre, Vincenzo Galilei, laudista reconocido en su tiempo quién mostró un interés particular sobre el estudio de la naturaleza. ${ }^{2}$ Aunque sus primeros años como académico no fueron sencillos, progresivamente se forjó un camino propio. Con el paso de los años logró establecer muy buenas relaciones con nobles y clérigos, en especial con Chistopher Clavius, cuyo prestigio era muy alto dentro de la comunidad científica y matemática de su tiempo. También, la influencia de los Medici

2 Existe un pequeño fragmento de Vincenzo Galilei en su Dialogo della musica antica $e$ della moderna donde refleja su carácter de investigador, y que posiblemente lo haya transmitido a su hijo: «Me parece que quienes confían sin más en la autoridad como prueba de una cosa cualquiera y no tratan de aducir alguna razón válida proceden de forma ridícula... Yo deseo... que se me permita plantear cuestiones libremente, así como responder sin ningún tipo de adulación, pues esto es lo que verdaderamente conviene a quienes buscan la verdad de las cosas» (Drake 1986: 45). 
(Ferdinando, Cósimo II) y, sobre todo, sus conversaciones y diálogos con la Gran Duquesa Cristina de Lorena, han sido de mucho beneficio para su carrera y para su interés en explicar apropiadamente las relaciones entre ciencia y religión.

Por otro lado, la Iglesia afrontaba muchos acontecimientos de gran magnitud. Algunos de ellos han sido la reforma católica, la contrareforma y, en especial, el Concilio de Trento (1545-1563), donde se abordó, a partir del conflicto con los protestantes, el tema de la interpretación de las Sagradas Escrituras. Shea y Artigas explican la importancia del Concilio:

La Iglesia católica deseaba subrayar la importancia de la Tradición y del Magisterio contra los protestantes, que rebajaban su relevancia [...] El Concilio se movía en ese contexto teológico, y nadie en aquellos momentos parece haber pensado que la ciencia en general, y menos todavía la hipótesis concreta del movimiento de la Tierra, recientemente propuesta por Copérnico, pudieran ser un asunto religioso. (2003:23)

Este aspecto será de mucha ayuda para Galileo cuando querrá sustentar que sus nuevos descubrimientos no contradicen los pasajes bíblicos ni atentan contra la Iglesia. Del mismo modo, las interacciones de Galileo con jesuitas han sido muy estrechas: en 1587 conoció a Christopher Clavius, director del entonces Colegio Romano de jesuitas y una gran autoridad en el mundo matemático. Intercambian cartas y se vuelven amigos. Cuando Galileo presenta sus descubrimientos a partir del uso del telescopio que él lo adapta para fines astronómicos, no solo Clavius lo apoya, sino gran parte de los jesuitas del Colegio Romano. Sin embargo, lo toman con cautela, en 
especial el cardenal Bellarmino, quien no obstante de estar complaciente con el respaldo de los jesuitas científicos hacia Galileo, tenía sus propias preocupaciones con respecto a cómo asumir estos nuevos descubrimientos a la luz de las interpretaciones de las Sagradas Escrituras. ${ }^{3}$

Con respecto al contexto científico, Galileo era ya partícipe de la llamada revolución científica: figuras como Leonardo Da Vinci, Nicolás Copérnico, Andrés Vesalio, Gerardo Mercator, entre otros, marcaban como sus precursores. ${ }^{4} \mathrm{Al}$ mismo tiempo, cuando era todavía profesor de matemáticas en Padua, había acaparado la atención de un joven profesor de matemáticas de Gratz: Johannes Kepler. En 1597, le envía un ejemplar de su Mysterium cosmographicum a través de un amigo y como agradecimiento, Galileo le responde con amplios elogios y atenciones. Aunque nunca existió una real amistad entre ellos (Kepler recibió a lo largo de su vida dos cartas de Galileo) Kepler evidenció muchos actos que acreditaban su admiración y su deseo de tener una real amistad hacia Galileo, tanto así que ya siendo astrónomo imperial de Praga defendió, incluso sin usar el telescopio, a Galileo y su Sidereus Nuncius en $1610 .^{5}$

Todos estos aspectos sin duda ayudarán a comprender el contexto en el que Galileo realizará sus estudios sobre la naturaleza. No obstante, es

3 Roberto Bellarmino (1542- 1621) fue un cardenal jesuita. Participó en el Concilio de Trento y fue el encargado de mejorar la edición de la Vulgata; participó en el proceso y la condena de la Inquisición contra Giordano Bruno y miembro de la Congregación del donde se encargaba de mantener la ortodoxia y la censura sobre la libre interpretación de las Sagradas Escrituras. Además, jugó un rol muy importante en el proceso a la teoría heliocentrica de Copérnico del 1616, siempre aconsejando moderación y prudencia a todos, incluido a Galileo, que de todos modos siempre quiso proteger. Desgraciadamente, murió antes del proceso a Galileo del 1632.

4 Paolo Musso sintetiza todo este recorrido. Véase Musso 2011.

5 Existe un capítulo muy interesante desde la visión de Koestler sobre la relación Kepler Galileo. El autor crítica severamente la actitud y la dejadez de Galileo hacia Kepler, que por cierto, siempre actuaba de manera estoica y desinteresada (Cf. Koestler 1986). 
necesario indicar que el momento determinante de su actividad científica ha sido desde la novedad del uso del telescopio para estudiar los cuerpos celestes y sus posteriores descubrimientos astronómicos a partir de ella. Estas implicancias han conllevado el buscar un nuevo modo de cómo estudiar el mundo que le rodea, desde una apertura a la novedad.

\section{LA CIENCIA PREGALILEANA: UNA LARGA HERENCIA SOBRE LA MIRADA REALISTA DE LA NATURALEZA Y EL QUEHACER FILOSÓFICO DE GALILEO}

Los estudios realizados por distintos historiadores y filósofos de la ciencia han intentado establecer, desde varios puntos de vista, los orígenes de la ciencia moderna. En verdad, habría que remontarse desde el redescubrimiento de los textos aristotélicos en Europa y el gran aporte técnico que hicieron los árabes al aplicar los principios aristotélicos siglos atrás y del cual lamentablemente no se podrá explicar detalladamente en este artículo. Mas sí podemos inferir que uno de los grandes problemas por el que muchos filósofos medievales defendieron ardientemente las teorías físicas de Aristóteles es porque asumían que, al ser un gran aporte filosófico y ético al pensamiento cristiano medieval, ${ }^{6}$ también debería ser una gran autoridad en los conocimientos del mundo natural. Por varios años se ha considerado así, ${ }^{7}$ y es muy comprensible la absolutización de la defensa del pensamiento aristotélico. Sin embargo, la física aristotélica era una física

6 Véase cómo Tomas de Aquino se emociona mucho de haber encontrado un modo de cómo explicar los grandes dogmas cristianos, y desarrolla las famosas cinco vías de la demostración de la existencia de Dios en su Suma Teológica a partir de su lectura de los textos aristotélicos.

7 El hecho de que el sistema geocéntrico mejorado por Tolomeo sea una herencia aristotélica importante a tal punto de que todo el mundo tardo antiguo y medieval lo han asumido por 15 siglos como una verdad física. 
a priori, partiendo desde el estudio de las esencias para poder explicar el mundo natural.

Es necesario aclarar cómo se entendía el estudio de las disciplinas con respecto a la realidad física y metafísica durante la Edad Media. Existía una gran diferencia entre matemáticos y filósofos. Stillman Drake (1986) explica que los matemáticos eran las grandes autoridades sobre la enseñanza de la astronomía. La astronomía era la disciplina que se encargaba de la medición exacta de ángulos y tiempos, además que buscaban las leyes que relacionen de manera sistemática estas mediciones. Por eso, los filósofos no la consideraban una verdadera scientia sino como una techne. En cambio, los filósofos naturales (es decir, los físicos), estudiaban los cielos a partir de la cosmología (siempre basándose en textos aristotélicos). Esta disciplina era la verdadera scientia en su sentido epistemológico. Esto quiere decir que los matemáticos medievales estudiaban la astronomía tolemaica que se basaba únicamente en la medición y el cálculo, quedando para los filósofos toda explicación causal o física y para esto, se partía de los principios a priori, metafísicos, especulativos y demás lógicos deductivos.

No obstante, esta única forma metodológica para estudiar tanto el mundo físico y justificarlo a partir de lo metafísico se irá cuestionando a partir de nuevos estudios y reflexiones. Este deseo de cambio es lo que se conocerá como la revolución científica. Para citar un ejemplo, Leonardo Da Vinci (1452-1519) fue uno de los primeros que ya había considerado el pensamiento matemático para interpretar el orden mecánico y necesario de toda la naturaleza; elimina de los fenómenos naturales toda intervención de fuerzas y de potencias animistas, místicas y espirituales (Cf. Reale y Antiseri 1999). Es verdad que todavía no posee ningún interés por la ciencia como corpus organizado de conocimientos ni la concibe como una actividad 
pública y colectiva, pero definitivamente ya es un precursor científico. Por tanto, la revolución científica va a modificar la imagen del mundo y la nueva ciencia se convertirá en una permanente indagación y razonamiento sobre el mundo natural de manera gradual (Cf. Reale y Antiseri 1999).

Es aquí donde empezará la grande discusión. ¿Cuál es el punto originario de la ciencia galileana para establecer la nueva ciencia y un nuevo método de estudio hacia el mundo físico?

\subsection{El origen del método científico de Galileo según Drake y Garín}

Uno de los motivos por las cuales Galileo es considerado el padre de la ciencia moderna es porque estableció de manera definitiva el método de la ciencia natural, es decir, a partir de sus cuatro componentes: (a) partir del estudio de las propiedades, (b) la necesidad de realizar experimentos y no solo simples observaciones, (c) las demostraciones matemáticas y (d) el rechazo al principio de autoridad, él establece el canon que conllevará el método científico (Cf. Musso 2011). Esto significa realizar un estudio propio de la naturaleza a partir de la ciencia experimental que supone una dirección teorética y práctica del estudio del mundo físico. Sin embargo, el aporte de muchos estudiosos es considerar solo la descripción del cambio metodológico, mas no hay una aproximación concreta de su origen. Posiblemente lo que se buscaba era un «origen» empírico, del método galileano, cuando a lo mejor era necesario partir del reconocimiento de una actitud personal influenciado por un contexto cultural. Para ellos, sería conveniente repasar primero, a partir de los aportes de los historiadores de la ciencia Stillman Drake y del filósofo Eugenio Garín, lo que consideran los factores del origen del método científico galileano. 
Drake indicará que uno de los factores de la ciencia moderna es el enfatizar el carácter empírico de las mediciones. «La nueva base de la ciencia galileana del movimiento residía en las cuidadosas mediciones, con lo que se empezó a sustituir la antigua búsqueda de causas por la moderna búsqueda de leyes físicas. [...] Galileo daba ya por sentado que la medición era la clave de la buena física» (1986: 59). Es verdad que para Galileo era necesario establecer la unión entre matemática y física, sobre todo la última como una aplicación de los métodos astronómicos al estudio del movimiento. Lo más interesante es que Drake sostiene que era común entre los innovadores de la época (también en Galileo) minimizar las nuevas técnicas y procedimientos y darles mayor prioridad a los descubrimientos: «Puede parecer un poco extraño, pero en la historia de la ciencia no es raro que las nuevas técnicas y procedimientos no se consideren en la época importantes en sí mismo, por más que los descubrimientos — que se tienen por más interesantes y significativos - no hubieran podido realizarse sin su concurso» (1986: 59). Para el juicio de la época era lo establecido (como en el caso de Leonardo da Vinci, explicado líneas atrás). No obstante, en el caso particular de Galileo esto cambia porque él sí era consciente de un nuevo cambio de método que posteriormente derivó a sus nuevos descubrimientos. Por otro lado, Drake apenas intuye un aspecto fundamental del cual nosotros enfatizaremos posteriormente, con respecto a las relaciones entre ciencia y religiosidad: «La medida es inherente a la ciencia; la verdad eterna queda para la fe, sea filosófica o teológica» (1986:63).

En cuanto a Eugenio Garín, este considera |1que el inicio de la ciencia moderna ha nacido en el seno del Renacimiento, pero no dentro de las universidades. Ha sucedido, según el estudioso italiano, en las zonas marginales a través de los nobles mecenas: 
En la Venecia de la segunda mitad del S. XVI existía un grupo de nobles cultos, preocupados por los intereses de su patria, pero abiertos al mundo, atentos a las voces y experiencias que de este les llegaban y ligados a las tradiciones religiosas y culturales, pero preocupados por no dejarse atrapar en ellas, y por responder con su propia palabra, fruto de sus esfuerzos y de su libertad, a los numerosos problemas que la época proponía a sus mentes y a sus corazones. (Garín1982: 118)

Es normal que, debido al intercambio cultural, los primeros signos han ido manifestándose en las periferias (por ejemplo — menciona- a las secretarias, las cortes y las academias); no obstante, fue en las universidades donde se tomó un argumento y se delimitó de manera racional estos cambios que irán siendo fundamentales para los nuevos estudios. Con respecto a Galileo, Garín realzará el aporte de Copérnico y de los matemáticos griegos (Arquímedes):

La transformación de su pensamiento no fue el producto de un conjunto de razones o experimentos particulares (muchos de los cuales ni siquiera seguros estamos de que los hubiera realizado), sino de la aceptación de una hipótesis general radicalmente nueva acerca del sistema del mundo, o sea, la teoría copernicana, que en el se combinaría con el reconocimiento de Arquímedes como maestro en el terreno de la metodología. (Garín 1982: 141)

Además, criticará mucho el intento de los historiadores modernos de la ciencia que buscan un modo de indicar entre varias personalidades científicas de sus países como "precursores de Galileo» (Garín 1982: 140). 


\section{LA IDEA DE DIOS COMO MISTERIO EN EL GÉNESIS DEL MÉTODO CIENTÍFICO DE GALILEO GALILEI}

Se referirá, sobre todo, a la minimización trascendental de los medievales. Este tema lo defenderá el físico Pierre Duhem (1996).

Lo que llama la atención es la confrontación, en primer lugar, con respecto a sus críticas muy severas a la Iglesia católica y la Inquisición en los años del Renacimiento y principios de la edad moderna. Lanza afirmaciones muy severas, por ejemplo, que la Iglesia ha rechazado totalmente el humanismo, callando todo tipo de progresos científicos debido a que las ideas nuevas son el temor de los conservadores: "Todo lo audaz, nuevo y positivo que había producido un siglo y medio de cultura fue obstaculizado, mutilado, ahogado» (1982: 122). No obstante, acepta que, a pesar de todo, la nueva ciencia no era irrespetuosa de la fe. En segundo lugar, la intuición genial que Garín enfoca con respecto a la separación metodológica entre filosofía natural y fe en Galileo:

La filosofía se separa de la fe: dos libros, dos lenguajes, dos maneras de leerlos. [...] La fe se mueve en un plano distinto; la ciencia no la toca; no la apoya ni la niega, no la reemplaza ni es capaz de confirmarla o desmentirla. [...] Exenta de presencias ultramundanas, la ciencia mundana reconoce la existencia de otra experiencia: la fe; $y$, una vez eliminada la confusión aristotélica entre física y teología, ya no puede haber conflicto entre uno y otro tipo de experiencia. (Garín 1982: 145)

Esta intuición inicial luego desembocará en lo que interpreta Garín con respecto a la religiosidad galileana. El estudioso la considera como un cristianismo positivo de función pedagógica y moral: 
Quizá aquí se plantee la pregunta más radical de Galileo. Esa visión totalmente terrestre del saber y del hombre, ¿deja realmente un margen para la fe? Ese vacío, que la religión quiere colmar, ¿es verdaderamente un sentido positivo de lo absoluto, o solo es la conciencia, completamente negativa, de un límite que la investigación ya no abriga la ilusión de superar? La respuesta de Galileo es un cristianismo sincero, al que asigna una función pedagógica y moral. Su lucha contra el peripatetismo se presenta al mismo tiempo como una lucha por la liberación de los hombres a través de la verdad y la fecundidad de la ciencia, y como una especie de nueva apologética de un Dios muy distinto del Dios de los filósofos. Su fe es serena, y su ciencia liberadora; los cielos que descubre, los instrumentos que construye, le infunden un sentimiento de alegría y de fuerza, de confianza. [...] Por eso, la proclamación de la verdad, a todos los hombres [...] adquiere para él el sentido de una misión. (1982: 146)

Es muy importante sugerir que esta interpretación de Garín corresponde a un tipo de cristianismo «renacentista» en Galileo. Esta actitud, en parte, se suele asociar fácilmente a partir de sus descubrimientos astronómicos, como si se quisiera etiquetar a un Galileo precristiano y poscristiano (renacentista) cuyo cambio se da a partir de estos descubrimientos. Sin embargo, se debe (y consideramos que es necesario) vislumbrar desde una mirada cristiana sin reducirla a temporalidades ni épocas. Sin un reconocimiento de un Dios cristiano como se entiende en su originalidad, la práctica pedagógica cristiana pierde su sentido esencial. Es por ello que es importante indicar que en él no se ve una simple actitud cristiana, sino que ella se da a partir del reconocimiento de Dios como 
Misterio y esta afirmación conllevaría a aceptar una realidad sin límites. Garín solamente es capaz de aproximarse un poco a ello, mas todavía no logra identificarlo del todo: «Dios es la raíz de todo, pero también está más allá de todo» (1982:166).

\section{Una aproximación hacia la originalidad metodológica}

En primer lugar, Galileo quería dar a entender que sus estudios estaban enfocados hacia otro horizonte. Debido a ello, en 1610, escribe una carta a Belisario Vinta (Secretario y asesor personal del Gran Duque de Toscana, Cósimo II, patrocinador de Galileo) donde pide ser llamado «Filósofo y Matemático» de la Corte (Cf. Shea y Artigas 2003). Para la época, «filósofo natural» era equivalente a lo que llamaríamos hoy científico. Galileo no asumió ser filósofo en el sentido tradicional, como si deseara «buscar una trascendencia» para la ciencia, sino filósofo en el sentido de «tomarse en serio" la realidad física y estudiarla a fondo. Quería ser visto como un científico que se ocupaba del mundo real, no solo de hacer cuentas. ${ }^{8}$ Este es el carácter unitario de la ciencia.

En segundo lugar, Galileo era un hombre de transición de épocas, pero con una novedad particular (como diría Garín); un sujeto capaz de ver dentro del actuar científico lo mismo que observaban sus contemporáneos pero además «miraba» desde un ángulo que el resto no podía, tal como reza la frase popular del filósofo húngaro Albert Szent-Györgyi: «Todo descubrimiento consiste en ver lo que todos han visto y en pensar en lo que nadie ha pensado». Galileo lo que mira es la inteligencia pura de la realidad, es decir, la capacidad grandiosa de los que es el mundo y su inmensidad. No se refiere únicamente a sorprenderse de ella, sino de darse cuenta que esto

8 Sígase la aclaración temática de Martínez (1995). 
responde a un por qué, a esto se le denomina tener un espíritu despierto, ${ }^{9}$ tener una apertura con la esperanza de encontrar algo positivo en ella. Esto se refleja en una carta que escribe Galileo a Belisario Vinta en 1611, luego de encontrarse con su viejo amigo Clavius y saber que sus observaciones junto a las de sus colegas jesuitas con respecto a los planetas mediceos (los satélites de Júpiter) todavía siguen muy complejos de decifrar y esto le causa cierta preocupación. La última parte de su carta indica algo novedoso: «Sin embargo, yo tengo gran esperanza de llegar a encontrarlos y determinarlos, y confío en Dios bendito que, así como me ha concedido la gracia de haber descubierto yo solo tantas maravillas nuevas llevado de su mano, me conceda que encuentre el orden absoluto de sus giros» (Shea y Artigas 2003:4445). En este pasaje, Artigas interpreta que la actitud que muestra Galileo en esta carta es signo de arrogancia y soberbia, puesto que se considera el único capaz de alcanzar este conocimiento y pide un amparo divino para llegar a sus designios. Sin embargo, no es una interpretación totalmente justa. Es cierto que la personalidad y el temperamento de Galileo distan mucho de ser la del devoto perfecto y pío; es más, frente a sus enemigos se mostraba extremadamente arrogante, irónico e iracundo, más cuando se trataba de acusaciones a sus novedades científicas o cuestionamientos sobre su modo de proceder. En este sentido, podemos indicar que Garín ha sido muy benévolo con la actitud altruista de Galileo. No obstante, esa mirada humana, esta tensión entre su voluntad y su reconocimiento de la grandeza del mundo es tan auténtica incluso en sus momentos caprichosos de desesperación e imprudencia, de arrogancia e ingenuidad frente a los acontecimientos de su vida (Cf.- Shea y Artigas 2003). Sin embargo, ese $9 \quad$ Una de las anécdotas de Galileo era su afán en descubrir una nueva forma de estudiar los cuerpos naturales partiendo de la expresión de Eureka de Arquímedes. A partir de este relato, Galileo intuyó que debía hacer algo similar: establecer un nuevo método en base a la observación de la realidad, respetando el objeto (Cf. Shea y Artigas 2003). 
tipo de estudio no impidió a Galileo reconocer que existen otros tipos de métodos con los que el hombre puede abrazar la realidad. Uno es lo que Giussani denomina certeza moral ${ }^{10}$ que no contradice el método científico. A partir de esta certeza moral, es posible que Galileo se descubra mirado, amado, buen católico e hijo obediente de la Iglesia. Esto no era una simple táctica política o moralista o simplemente metodológica. Era la expresión de un científico cristiano que ha madurado en sus pensamientos. Lo que le caracterizaba, por tanto, era la honradez consigo mismo que le daba este carácter humanamente científico. Es posible que a partir de ello se puede entender su impaciencia debido a que su apertura y permanente asombro a sus descubrimientos denota un reconocimiento que lamenta no ver en sus contemporáneos: admitir cuándo la realidad se impone. Es ésta actitud la que refleja el Galileo científico y cristiano, saberse descubridor de algo nuevo porque admite que el mundo es más grande que él. Lo que aporta, en verdad, es algo pequeño frente la realidad inmensa y misteriosa.

Esto se evidenciará en una carta muy importante hacia la señora Cristina de Lorena, Gran Duquesa de Toscana. El contexto de la carta es muy importante, puesto que ella, siendo la viuda del Gran Duque Ferdinando y madre de Cósimo II de Médici, el sucesor del Ducado de Toscana, gozaba de mucha influencia y podría menguar los conflictos ocasionados por una carta redactada en 1613 a su querido amigo y discípulo Benedetto Castelli. El contexto indica que Castelli, durante una comida con los Duques, se puso a argumentar frente a la Gran Duquesa Cristina sobre la compatibilidad entre el copernicanismo y las Sagradas Escrituras. Para Galileo no existía

10 Luigi Giussani indica la necesidad de una forma diferente de usar la razón: «Para el descubrimiento de verdades o certezas concernientes al comportamiento humano, hay que usar la razón de manera diferente; en caso contrario su uso deja de ser razonable. Por ejemplo, pretender definir la validez del comportamiento humano mediante un método científico no es un procedimiento adecuado» (2008:37). 
ninguna incompatibilidad entre ellas, así que decide ayudar a Castelli escribiéndole una carta donde expresa sus conocimientos teológicos y su claridad metodológica del mundo natural. Sin embargo, nadie se imaginaría que esta carta conllevaría a un gran conflicto. Vale decir que esta carta fue interpretada por algunos teólogos como una provocación a enseñarles cómo debían interpretar la Biblia por lo que llegaron al Santo Oficio acusaciones sobre las «libres interpretaciones» de Galileo con respecto a las Sagradas Escrituras. Es a partir de ello que él decide sustentar sus ideas y el resultado fue una carta enviada en 1615 a la Archiduquesa y en ella Galileo intenta explicar que la teoría copernicana no contradice las Sagradas Escrituras. Al mismo tiempo, también desarrolla un análisis magistral sobre el método del trabajo científico en relación al texto bíblico, tal como lo indica en un párrafo: «Me parece que, al discutir los problemas naturales, no se debería partir de la autoridad de los pasajes de la Escritura, sino de la experiencia de los sentidos y de las demostraciones necesarias. Porque la Sagrada Escritura y la naturaleza proceden igualmente del Verbo divino» (Galilei 1615). Él era muy consciente de que su nuevo método no es incompatible con la fe cristiana, es más, intenta delimitar más el estudio de la naturaleza para evidenciar las obras de Dios. Por ello, considera que es absurdo que se deba desconfiar de los sentidos y de la razón para explicar el mundo: «No puedo creer que Dios nos haya dotado de sentidos, palabra e intelecto, y haya querido, despreciando la posible utilización de éstos, darnos por otro medio las informaciones que por aquéllos podamos adquirir» (Galilei 1615).

Es verdad considerar que esta actitud de Galileo contrasta con una política eclesial que, a partir de los problemas que tenía con los protestantes, asumió una actitud muy cauta, manteniendo un recelo muy voraz con respecto a publicaciones de libros que comprometan a la Tradición y el 
Magisterio de la Iglesia. ${ }^{11}$ Galileo, preso del contexto y de una mentalidad que distanciaba de lejos a sus contemporáneos, tuvo que, a regañadientes, aceptar.

\section{LA FE CRISTIANA EN LA CREACIÓN Y DIOS COMO MISTERIO EN EL TRABAJO CIENTÍFICO DE GALILEO}

Otro aspecto muy resaltante es la influencia medieval en la concepción científica de Galileo. Pierre Duhem, en sus Études sur Léonard de Vinci (Cf. Jaki 1996), ${ }^{12}$ indica que la mecánica de Galileo tiene sus orígenes en la Edad Media cristiana a partir de los aportes de la Escuela de París, liderada por Oresme y Buridano: ellos concibieron dicha mecánica dejándose guiar por la observación y poco a poco se han ido alejando de los estudios aristotélicos. Además, otro factor fue importante en determinar el cambio metodológico galileano, o sea, la fe cristiana en la creación del mundo, que los Griegos

11 La preocupación que tenía la Iglesia de ese entonces era muy comprensible. El Santo Oficio y la Congregación del Índice fueron dos congregaciones nacidas en el seno del Concilio de Trento con el objetivo de mantener la ortodoxia de los fieles frente a los ataques protestantes que buscaban una forma libre de interpretar las Sagradas Escrituras. Pío V suavizó la Congregación del Índice después del Concilio de Trento para que se dedicara a vigilar, editar y, si era necesario, censurar textos que comprometían los dogmas de la Iglesia Católica. En varias ocasiones, Galileo tuvo que pasar muchas veces corrigiendo, modificando y aclarando diversas temáticas antes de que un libro suyo tenga la autorización de ser publicado. Por otro lado, la figura del cardenal Bellarmino era una pieza clave en este objetivo. Con la comunidad jesuita estableció que ningún profesor de ciencias en las instituciones educativas jesuitas podía introducir nuevas opiniones sin la autorización respectiva de sus autoridades y por ningún motivo un laico podía interpretar públicamente pasajes bíblicos sin asesoría eclesial. Además, los conflictos políticos entre Roma con los demás reinos católicos y no católicos colocaban en una situación tensa los tratos diplomáticos.

12 Esta afirmación proviene del físico francés Pierre Duhem (1861-1916). No solo era una gran autoridad en el mundo científico, sino un católico practicante muy serio. En dicho libro, Jaki evidencia la gran tesis de Duhem: descubrir y sustentar los orígenes medievales de la ciencia newtoniana. 
en cambio no concebían, pues esto implica que el mundo sea así como es por una libre decisión de Dios, lo que implica a su vez que sus propiedades no se puedan deducir de ningún principio metafísico, sino solo se puedan descubrir directamente en la naturaleza, lo que representa la justificación teórica del primer principio del método galileano (Cf. Musso 2011).

En verdad, no es la única vez que se puede reconocer esto en un científico, casualmente creyente. Por ejemplo, esto se repite en la figura de Pierre Duhem en el S. XIX, del cual Jaki lo describe: «Su física era la de un creyente, o más bien de su fe católica. Esta fe se basaba en dos proposiciones cuya aceptación implicaba una adhesión sin salvedades al realismo. Una de estas dos proposiciones consistía en el primer dogma del credo: la creencia en el Padre Todopoderoso, Creador del Cielo y de la Tierra y de todas las cosas visibles e invisibles» (1996: 71-72). Es menester aclarar que no se está sugiriendo que los creyentes de tradición greco cristiana son verdaderamente científicos, sino que la facilidad de estos dos aportes mencionados permite en el hombre poseer una mirada más trascendental, que de esto se trata el trabajo científico y el modo cómo Galileo establece los parámetros del método de la ciencia natural. Pero esta mirada no es propiamente la mirada del hombre moderno naciente. Es necesario hacer un apartado sobre la mentalidad moderna con respecto al mundo y la realidad.

\subsection{La transición de la mentalidad}

Luigi Giussani en La conciencia religiosa en el hombre moderno realiza una comparación interesante sobre el cambio de la mentalidad entre el hombre medieval y el hombre moderno con respecto al mundo y a Dios. De algún modo, las circunstancias han cambiado: el hombre de la Edad Media miraba a Dios como el centro de todo la vida humana, toda la concepción del 
mundo y del hombre vivía muy consciente de la participación del Creador en la realidad. El ideal del hombre no estaba en función de sí mismo, sino en función a Dios y esta expresado en el santo, no tanto porque sea perfecto, sino porque era la tendencia de alcanzar su realización plena en Dios (Cf. Giussani 1986) ${ }^{13}$ ¿A qué se debe este cambio? En verdad, no hay una respuesta clara al respecto. Giussani no logra responder por qué se da este cambio. Pero, de algún modo, ha marcado una influencia también en el mundo científico. Duhem explica que el concepto modernocontemporáneo de la ciencia se ha reducido en su práctica a considerar como fundamentos axiomas que ninguna razón puede negar, hechos y certezas a partir de los sentidos estructurados bajo principios rigurosos controlados por experimentos; mientras que los dogmas religiosos provienen de fundamentos sentimentalistas y carentes de razón. Evidentemente los modernos se olvidaron, siguiendo la tesis de Duhem, que gran parte de la edificación científica moderna ha sido por hombres que nunca confrontaron la ciencia contra la religión (Cf. Duhem 1991). Regresando con Galileo, siempre ha considerado la presencia divina, incluso en los momentos más difíciles de su vida, como una compañía y no como un castigo.

Ese reconocimiento que mantuvo Galileo es la actitud más libre del científico, porque en vez que asumir el rol de conquistador, asume el papel de conquistado y testigo de tantas maravillas. En verdad, esta actitud siempre estuvo presente en él. La ciencia necesita de esta humanidad para funcionar bien, como ya Galileo ha demostrado, no solo en teoría, sino también en su práctica científica. Un bello pasaje citado por Artigas con

13 A la par de la visión del hombre del Medioevo, expone un análisis crítico del humanista del renacimiento « [...] No importa en qué campo, pero es necesario que la vida tenga éxito... El dios, por tanto, no lejano y aislado de la existencia, sino operante y partícipe de las vicisitudes humanas, es el éxito» (Giussani:1986:19). 
respecto al texto de Il Saggiatore, relata una parábola donde muestra a un Galileo consciente de los límites del conocimiento humano:

Una vez en un lugar solitario, vivía un hombre al que la naturaleza había dotado con una mente muy penetrante y de una extraordinaria curiosidad. Como pasatiempo criaba diversos pájaros. Disfrutaba mucho con su canto, y con gran asombro iba observando cómo conseguían, cada uno a su modo, transformar el mismo aire que respiraban en cantos muy diferentes y bellos. Sucedió que una noche oyó un sonido delicado junto a su casa [...] y al llegar al camino encontró a un pastorcito que soplando [...] producía aquellos sonidos, semejantes a los pájaros, pero de modo muy diferente. [...] Advirtió que, si no hubiera encontrado a aquel muchacho, nunca habría aprendido que existen en la naturaleza dos modos diferentes de producir voces y cantos delicados. (Shea y Artigas 2003: 114)

Por muy seriamente que se intente comprender la naturaleza, no se debe olvidar nunca que aquello que se cree que se puede producir de un modo, puede ser producido por la naturaleza de muchas otras maneras (es decir, si a Dios le da la gana de crear algo, lo hace de la forma que él —y no nosotros - quiera). Este es el principio de contingencia como consecuencia de esta fe cristiana en la creación. Aunque parezca obvio, no lo es para el pensamiento moderno de ese entonces, a excepción de Galileo y algunos pocos más. Tal como nos revela el mensaje que cita Galileo al final de su parábola cuando el hombrecillo de la historia, confiado en su conocimiento de cómo se producen los sonidos, cogió una cigarra y, al no encontrar el origen de su canto: 
[...] hincó su aguja con tanta profundidad que atravesó a la criatura, quitándole de la vida junto con su voz, de modo que no fue capaz de saber dónde tenía su origen el canto. Esta experiencia le llevó a desconfiar de su saber, de modo que, cuando le preguntaban cómo se originaban los sonidos, respondía que conocía algunas maneras, pero que estaba seguro de que existían mil otros modos desconocidos e inimaginables. (Shea y Artigas: 2003:114-115)

Cada persona encaminada hacia la investigación, de cualquier tipo, debe tener en cuenta el aspecto de lo insondable que puede ser la realidad y asumirlo no con arrogancia, sino con sencillez. Este aspecto es muy crucial y determinante en nuestras vidas. Giussani lo planteaba como el problema de la opción del cual hasta el día de hoy se convierte en el vértice de nuestra libertad: "Toda esta situación descrita hasta ahora, con sus consecuencias, no es el fruto de una investigación más seria del hombre sobre sí mismo, sino de una opción. [...] Es, pues, una posición que el hombre asume, es una libre elección» (Giussani 1986: 49). Solo una mirada sincera frente a la realidad permite esta condición. De algún modo, esto se pudo lograr gracias a una "autoconciencia" (reconocimiento) de ser como creatura, como un ser que está en relación con lo que le rodea (realidad) y de algún modo se ha dado una tensión hacia el misterio de las cosas, que la realidad es más grande que uno mismo y se reconoce como parte de un todo, de un infinito, de una relación con ella.

\section{CONCLUSIONES}

La nueva visión galileana de la ciencia es uno de los acontecimientos más grandes de la historia del conocimiento sobre la naturaleza. Esta visión no 
es, como se piensa, el fruto de una gran visión o perspectiva meramente conceptual o racionalista. Esto se da, primero, por una capacidad de mirar la realidad como un misterio, inmenso y absoluto que logra percibir Galileo con un estupor original. Sin embargo, esta forma de «realismo» es producto del reconocimiento de que él, ante a la naturaleza, es un testigo y no un protagonista, que no es autónomo; es un caminante, que no lo domina todo, sino que se reconoce como dependiente. Por tanto, esta concepción de «dependencia» la reconoce con humildad y no con resignación. Esta relación libre de Galileo con Dios se da en la opción de que él lo acepta dentro de su libertad y esto marca el punto definitivo del carácter de la ciencia moderna. Este crucial momento es vertiginoso para comprender el aspecto crucial del papel que juega la ciencia moderna, tal como lo afirma muy apropiadamente Jaki: «O la ciencia se considera como el sello supremo de la autonomía del hombre o bien como un don concedido desde lo alto» (1996:119).

Lo mismo ha llegado a reconocer, únicamente en base a su experiencia personal de la ciencia, el gran físico alemán Werner Heisenberg, que recordando el día en que hizo su descubrimiento más importante la fórmula del principio de indeterminación - que está en la base de la mecánica cuántica y luego de la teoría atómica moderna, expresa de modo explícito de un «don» que ha recibido, pese a que no creía en un Dios personal: «Y ahora [...], todo el territorio de las relaciones internas de la teoría atómica se ha desplegado repentinamente ante mis ojos con claridad. Que estas relaciones internas muestren, en toda su abstracción matemática, un grado de increíble sencillez, es un don que solo podemos aceptar con humildad. Ni siquiera Platón habría podido creer que fueran tan bellas. 
Estas relaciones, en efecto, no pueden ser inventadas. Existen desde la creación del mundo» (Heisenberg 1971: 71-72).

Finalmente, la cuestión es reconocer que el hombre es capaz de mirar el mundo a través de una disposición de libertad frente al Misterio. Galileo lo tuvo, como creyente y científico. Esto no quiere decir que uno tiene que ser creyente para que sea buen científico, sino que la disposición de Galileo, frente a otros (Cf. Musso 2011), ${ }^{14}$ ha sido de completa admiración por el Misterio. Esto quiere decir reconocer que la realidad es más grande que uno y esto es posible cuando se contempla la presencia de lo divino (el cristiano lo llama comúnmente Providencia) en toda la realidad, incluso en los momentos más difíciles que tuvo que vivir.

14 En referencia a Descartes, el autor elabora un análisis profundo entre la relación entre Descartes y Galileo con respecto a la noción del Misterio: «Intendiamoci, è senz'altro vero che almeno per molti autori la motivazione ultima di tale concezione sia stata effettivamente quella di "far fuori" la trascendenza. Però non sempre è così. E, in particolare, non è così per Cartesio, che fu certamente anch'egli un "sincero credente" come Galileo, anche se non molto appassionato. [...] Né tantomeno su quello della moralità personale: anzi, da questo punto di vista Cartesio fu molto più coerente che non Galileo, il quale ebbe tre figli fuori dal matrimonio, scrisse un'ode che esaltava le taverne e i bordelli [...]. Ma, con tutti i suoi difetti, Galileo aveva una cosa che a Cartesio invece mancava completamente: il senso del mistero ' [... ] e che consiste essenzialmente nel riconoscimento che la realtà è più grande di noi. [...] E infatti, non a caso, Galileo trascorse tutta la sua vita in un rischio continuo» (Musso 2011: 215-126). 


\section{REFERENCIAS}

DraKe, Stillman

1986 «Los Primeros años de Galileo». En Galileo. Traducción de A. Elena. Serie El libro de bolsillo, humanidades. Madrid: Alianza Editorial.

Galilei, Galileo

2006 [1615] Carta a Cristina de Lorena. Biblioteca Virtual Miguel de Cervantes. <http://www.biblioteca.org.ar/libros/133541.pdf>. Consulta hecha en 09/10/2014.

Garin, Eugenio

1982a «Galileo y la cultura de su época». En Ciencia y vida civil en el renacimiento italiano. Traducción de R. Pochtar. Serie Ensayistas. Madrid: Taurus.

1982b "Galileo Filósofo». En Ciencia y vida civil en el renacimiento italiano. Traducción de R. Pochtar. Serie Ensayistas. Madrid: Taurus. 
LA IDEA DE DIOS COMO MISTERIO EN EL GÉNESIS DEL MÉTODO CIENTÍFICO DE GALILEO GALILEI

GIUSSANI, Luigi

1986

La conciencia religiosa en el hombre moderno. Traducción de José Miguel Oriol. 2. ${ }^{\text {a }}$ edición española. Madrid: Ediciones Encuentro.

2008

El sentido religioso. Traducción de José Miguel Orión, Cesare Zaffanella y José Miguel García. 2. ${ }^{\text {a }}$ edición peruana. Volumen 1. Lima: Fondo Editorial UCSS- Encuentro.

HeisenBerG, Werner

$1971 \quad$ Physics and beyond: encounters and conversations. New York: Harper \& Row.

JAKI, Stanley

1996 La ciencia y la fe: Pierre Duhem. Traducción de Godofredo Iommi Amunátegui. Madrid: Ediciones Encuentro.

KoestLer, Arthur

1986 «Kepler y Galileo». En Kepler. Traducción de Domingo Santos. Barcelona: Salvat Editores.

MartineZ, Rafael

1995 «La filosofía de Galileo y la conceptualización de la causalidad física». En Thémata: Revista de filosofía. <http://institucional. us.es/revistas/themata/14/03\%20Martinez.pdf>. Consulta hecha en $21 / 10 / 2014$. 
JANINA NAVARRO LINARES

Musso, Paolo

2011 La scienza e l'idea di ragione. Milano: Mimesis Edizioni.

Reale, Giovanni; Dario Antiseri

1999 Historia del pensamiento filosófico y cientifico. Versión castellana de Juan Andrés Iglesias. Tomo segundo: del humanismo a Kant. Barcelona: Herder.

SheA, William; Mariano Artigas

2003 Galileo en Roma. Crónica de 500 días. Madrid: Ediciones Encuentro. 